\title{
A ESCOLARIZAÇÃO DE ALUNOS/AS DE CIRCO: ENTRE O DESEJO E A
}

\section{REALIDADE}

\author{
Ailmo Xavier Soares ${ }^{1}$, Universidade Federal de Campina Grande - UFCG/CFP \\ ailmoxaviersoares@gmail.com
}

Ivanalda Dantas Nóbrega Di Lorenzo², Universidade Federal de Campina Grande -UFCG/CFP

\author{
ivanaldadantas@gmail.com
}

\begin{abstract}
RESUMO
Este ensaio é um estudo sobre os processos de escolarização dos alunos/as de circo no ensino básico nas distintas escolas da rede pública e privada. No Brasil, existem inúmeros circos constituídos por instituições familiares ou redes empresariais, os integrantes geralmente são: crianças, jovens e adolescentes que estão matriculados nas escolas, porem grande parte desse público por motivos distintos, não faz parte desse universo. O objetivo geral consiste em analisar o processo de escolarização dos alunos/as de circo nas instituições públicas e privadas de ensino. Os objetivos específicos são: 1) conhecer as políticas públicas voltadas para a educação itinerante, 2) identificar as potencialidades da educação para esses grupos, 3) promover uma discussão sobre os desejos e a realidades da escolarização na perspectiva dos discentes. A metodologia utilizada para a realização desse trabalho consistiu em um levantamento bibliográfico a partir de livros, artigo e documentos oficiais. Aplicamos também um questionário com alunos/as de circo. Nesse sentido, um aluno/a para ter acesso a escola apresenta uma série de dificuldades dependendo de suas funções nas atividades circenses, este enfrenta barreiras decisivas gerando muitas vezes a descontinuidade da formação e consequentemente a auto exclusão.
\end{abstract}

Palavras-Chaves: Circo; Educação itinerante; Políticas públicas.

\section{THE SCHOOLING OF CIRCUS STUDENTS: BETWEEN DESIRE AND REALITY}

\begin{abstract}
This essay is a study about the processes of schooling of students that live in a circus in basic education in the different schools of the public and private teaching network. In Brazil, thereare numerous circuses consisting of family institutions or business networks, the members are usually: children, youth and adolescents who are enrolled in schools, but a large part of this public for different reasons, is not part of this universe The general objective is to analyze the process of schooling of circus students in public and private educational institutions. The specific objectives are: 1) to know public policies for itinerant education; 2) to identify the potentialities of education for these groups; 3 ) to promote a discussion about the desires and realities of schooling from the perspective of the students. The methodology used to perform this work consisted of a bibliographical survey from books, articles and official documents. We also applied a questionnaire with circus students. In this sense, a student to have access to the school presents a series of difficulties depending of their
\end{abstract}


functions in the circus activities, this faces decisive hindrances often generating the discontinuity of the formation and consequently the self exclusion.

Keywords: Circus: Itinerant education; Public policy.

\section{LA ESCOLARIZACIÓN DE ALUMNOS/AS DE CIRCO: ENTRE EL DESEO Y LA REALIDAD}

\section{RESUMEN}

Este ensayo es un estudio sobre los procesos de escolarización de los alumnos / as de circo en la enseñanza básica en las distintas escuelas de la red pública y privada. En Brasil, existen innumerables circos constituidos por instituciones familiares o redes empresariales, los integrantes generalmente son: niños, jóvenes y adolescentes que están matriculados en las escuelas, pero gran parte de ese público por motivos distintos, no forma parte de ese universo. El objetivo general consiste en analizar el proceso de escolarización de los alumnos / as de circo en las instituciones públicas y privadas de enseñanza. Los objetivos específicos son: 1) conocer las políticas públicas dirigidas a la educación itinerante, 2) identificar las potencialidades de la educación para estos grupos, 3) promover una discusión sobre los deseos y la realidad de la escolarización en la perspectiva de los alumnos. La metodología utilizada para la realización de ese trabajo consistió en un levantamiento bibliográfico a partir de libros, artículos y documentos oficiales. También aplicamos un cuestionario con alumnos / as de circo. En ese sentido, un alumno / a para acceder a la escuela presenta una serie de dificultades dependiendo de sus funciones en las actividades circenses, éste enfrenta barreras decisivas generando muchas veces la discontinuidad de la formación y consecuentemente la auto exclusión.

Palabras-Llaves: Circo; Educación itinerante; Políticas públicas.

\section{INTRODUÇÃO}

Neste ensaio apresentamos reflexões parciais do estudo monográfico em andamento, no curso de Licenciatura em Geografia, do Centro de Formação de Professores (CFP), Universidade Federal de Campina Grande (UFCG), o qual tem como objetivo discutir sobre os processos de educação itinerante e de escolarização de educandos/as, artistas circenses, na Educação Básica, nas distintas escolas da rede pública e privada, no município de Cajazeiras, Paraíba e entorno.

No Brasil, existem inúmeros circos constituídos por instituições familiares ou redes empresariais, nos quais os integrantes geralmente são: crianças, jovens e adolescentes que estão matriculados nas escolas da rede pública e privadas de ensino, porém grande parte desse público por motivos distintos, não consegue acessar a escola em condições de igualdade. 
Para a compreensão da temática abordada elegemos como objetivo geral deste estudo analisar o processo de escolarização dos educandos/as de circo nas instituições públicas e privadas de ensino. Para alcançar o objetivo proposto, traçamos os seguintes objetivos específicos: 1) conhecer as políticas públicas voltadas para a educação itinerante, 2) identificar as potencialidades da educação para esses grupos, 3) promover uma discussão sobre os desejos e a realidade da escolarização na perspectiva dos/as educandos/as circenses.

Trata-se de um estudo de caso de natureza aplicada realizado a partir de uma abordagem qualitativa dos dados obtidos (PRODANOV \& FREITAS, 2013). Outra metodologia utilizada foi a pesquisa de campo, a qual segundo Marconi \& Lacatos, (2010, p.169) "É aquela utilizada com o objetivo de conseguir informações e/ou conhecimentos acerca de um problema, para qual se procura uma resposta, ou de uma hipótese, que se queira comprovar, ou, ainda, de descobrir novos fenômenos ou a relação entre eles".

Realizamos pesquisa bibliográfica a partir de levantamento teórico sobre a temática em trabalhos acadêmicos, livros, artigos e documentos oficiais públicos que estabelecem as diretrizes da educação itinerante.

Aplicamos um questionário com educandos/as de circo, a partir do qual transcrevemos as respostas como foram descritas pelos participantes. Entre os questionamentos, elencamos as seguintes perguntas: Como você é recebido/a pelos agentes escolares? Nas escolas existe a valorização das atividades circenses? Como os educandos/as de circos são avaliados pelos professores? Qual a relação entre os colegas e professores na sala de aula? Quais as facilidades e dificuldades para que um educando/a de circo possa estudar?

Ao contrário do que se afirma comumente de que o circo está em decadência como expressão de uma cultura viva, durante a pesquisa ouvimos de um palhaço de circo, no mês de julho de 2017, no município de Cajazeiras - PB: “O circo só irá morrer quando uma criança deixar de existir", nessa perspectiva, no mundo mágico do picadeiro, é possível viver e reviver as potencialidades e dificuldades do circo em um sistema perverso, que oscila entre a inclusão e exclusão, desestabilizando a importância da cultura e a atividade circense.

Dessa forma, para que possamos compreender a dinâmica e, a organização das atividades circenses, nos diferentes períodos históricos faremos neste trabalho, no primeiro 
momento, uma breve análise do histórico do circo no Brasil. E num segundo momento, uma discussão sobre a educação itinerante desse grupo destacando os pontos positivos e negativos do sistema educacional frente ao público em foco.

Nessa perspectiva, investigamos como a escola se coloca frente a esse público de educandos/as circenses. Dessa forma, buscaremos compreender o intuito das políticas públicas de educação itinerante.

\section{BREVE PANORAMA DA HISTÓRIA DO CIRCO NO BRASIL}

Desde a antiguidade a arte circense está presente em algumas civilizações. No Século XVIII, as atividades circenses se desenvolviam com grande intensidade no Continente Europeu. E, a partir do Século XIX, o Brasil passa a ser cenário das expedições circenses em pontos estratégicos do território. De acordo com Silva \& Abreu (2009, p. 22),

Desde os primeiros trinta anos do século XIX, o país começou a fazer parte da rota de turnês de circos estrangeiros, que desembarcavam em portos como Salvador e Rio de Janeiro, os artistas que chegavam eram geralmente contratados por empresários, outros grupos vinham com poucos utensílios de trabalho e realizavam suas atividades em praças públicas, feiras e festividades locais.

Para Cordeiro (2015 p.15), o circo tem suas origens marcadas pela imigração de povos europeus, em sua maioria ciganos que começaram a fazer pequenos espetáculos e, posteriormente, se envolveram com brasileiros e criaram as famílias tradicionais circenses, marcadamente presentes no cenário atual. Conforme Silva \& Abreu, (2009, p. 140),

O circo certamente era a única diversão que chegava até muitas regiões do Brasil. Levava o exótico, como os animais ou as fantásticas proezas realizadas com os corpos; encenava esquetes, pequenas comédias e peças teatrais, nunca antes vistas pela maior parte da população. O circo nesse período, qualquer que fosse o espetáculo apresentado [...] viveu uma fase de sucesso, marcando fortemente o imaginário da população no interior do País. 
De acordo com os autores, o circo era, em algumas áreas do território brasileiro, a única atividade de lazer das comunidades. Constituído por uma gama de atrações envolvendo vários elementos das artes circenses, em diferentes momentos históricos, perpassou por significativas transformações nas formas e funções, marcando o imaginário da sociedade brasileira.

É importante destacar, que neste espaço, existe um universo de informações desconhecidas pelo público, dentre elas a sazonalidade de apresentações, pois nem sempre estão desenvolvendo a atividade circense, bem como durante o período que não estão apresentando os espetáculos, estes grupos vivem como pessoas comuns, com problemas e dificuldades como qualquer cidadão, a exemplo do acesso à educação, tendo em vista que se constituem como povos itinerantes.

Nos circos, existem pessoas que frequentam escolas, porém, alguns integrantes, que estão na faixa etária escolar, não conseguem acessá-la. Dessa forma, para compreender as potencialidades e dificuldades da educação para esse grupo, faremos a discussão sobre o processo de escolarização desses/as educandos/as itinerantes na Educação Básica.

\section{A EDUCAÇÃO ITINERANTE DE ARTISTAS CIRCENSES E AS POLÍTICAS PÚBLICAS}

O circo é o maior símbolo de itinerância da contemporaneidade. Aqueles que estão situados nessa instituição cultural adentram os múltiplos territórios, entre eles, o espaço escolar. Há permanência de um circo em uma cidade varia conforme a dinâmica socioeconômica, dependendo da aquisição da lucratividade que os espetáculos possam gerar, continuam no exercício de suas atividades, quando sucede o processo inverso, mudam para outro lugar.

Nessa perspectiva, surge a inquietação de analisar como esses grupos participam dos processos de ensino e aprendizagem das escolas, já que seu modo particular de vida é pautado na itinerância. 
Para discorrer sobre a escolarização de um educando circense, em algumas instituições de ensino público e privado do território brasileiro, faz-se necessário o levantamento de algumas questões importantes, para que possamos averiguar se as políticas públicas realmente asseguram o acesso e à permanência com sucesso desse grupo, na Educação Básica.

Conforme a Constituição Federal (BRASIL, 1988) no Art. 29, e a Lei nº 6.533, de 24 de maio de 1978 (BRASIL, 1978), é assegurado o direito à educação aos filhos dos profissionais Artistas e de Técnico em Espetáculos de Diversões, grupos circenses entre outros:

Art. 29. Os filhos dos profissionais de que trata esta Lei, cuja atividade seja itinerante, terão assegurada a transferência da matrícula e consequente vaga nas escolas públicas e nas instituições particulares locais, na faixa etária de 4 (quatro) a 17 (dezessete anos), mediante a apresentação de certificado da escola de origem.

Parágrafo único. Na falta da documentação prevista, é vedado à escola não efetivar a matrícula, cabendo à instituição aferir o grau de desenvolvimento e experiência do candidato de modo a permitir a sua inscrição na série ou etapa adequada. (BRASIL, 2012,p.3)

Teoricamente, a referida Lei possibilita o direito em condições de equidade com relação aos ao acesso e à permanecia dos educandos/as, artistas circenses, na escola, desde as séries iniciais do Ensino Fundamental I ao Ensino Médio. Mas, apresenta fragilidades no que refere à exigência de apresentação de certificado das escolas antecedentes, devido algumas instituições desconhecerem o regulamento legal, bem como de certo modo, muitas vezes se negam ao atendimento a esse público.

Os tempos de acesso e permanência desse público nas instituições escolar e pelos educandos/as itinerantes de circos são imprevisíveis, desde a chegada e, consequentemente o afastamento do espaço escolar, para o estabelecimento noutra instituição. Segundo um diretor de escola entrevistado, o acompanhamento desse público torna-se insuficiente, pois o tempo exíguo da permanência daqueles na escola contribui para a dificuldade na organização documental necessária exigida legalmente. 
Após receber uma serie de reclamações, advindas de famílias circenses, sobre a educação, o Deputado Federal pelo Estado de São Paulo, Francisco Everardo Oliveira Silva, conhecido como Tiririca, também artista circense, propôs alterações no Projeto de Lei $n^{\circ}$ 3.543 - A (BRASIL: 2012, p. 3), a fim de facilitar os processos de ensino/aprendizagem desse público.

[...] A comunidade circense tem recorrentemente trazido a esta Casa a informação de que esse dispositivo legal não é cumprido pelas escolas. Muitas instituições de ensino fundamental e médio, quando procuradas pelos circenses, afirmam não ter vagas disponíveis. Outras se furtam à responsabilidade de fornecer, em tempo hábil, a certificação necessária para a transferência dos alunos oriundos de famílias de circo. Diante da falta dos documentos exigidos, grande parte das escolas recusa-se a efetivar a matrícula das crianças e jovens circenses, ainda que o direito à educação de qualquer brasileiro na faixa de quatro a dezessete anos seja garantida pela Constituição Federal

Tal Projeto de Lei acrescenta no Art. 29, da Lei $\mathrm{n}^{\circ}$ 6.533, de 24 de maio de 1978 (BRASIL, 1978), que na ausência de certificado da escola de origem, é de responsabilidade das instituições de ensino efetivar a matrícula dos educandos/as na faixa etária. Propõe ainda, que a instituição de ensino deve aferir o grau de desenvolvimento e experiência do candidato permitindo a sua inscrição na série ou etapa adequada ao processo de escolarização. Isso, com o objetivo de eliminar qualquer entrave burocrático que impeça a matricula e, consequentemente a permanência dos estudantes nas instituições.

Também em maio de 2012, o Conselho Nacional de Educação (CNE) (BRASIL, 2012) define as diretrizes para o atendimento de crianças, adolescentes e jovens em situação de educação itinerante.

Art. $3^{\circ}$ Os sistemas de ensino, por meio de seus estabelecimentos públicos ou privados de Educação Básica deverão assegurar a matrícula de estudante em situação de itinerância sem a imposição de qualquer forma de embaraço, preconceito e/ou qualquer forma de discriminação, pois se trata de direito fundamental, mediante autodeclaração ou declaração do responsável.

$\S 1^{\circ}$ No caso de matrícula de jovens e adultos, poderá ser usada a autodeclaração.

$\S 2^{\circ}$ A instituição de educação que receber matrícula de estudante em situação de itinerância deverá comunicar o fato à 
Secretaria de Educação ou a seu órgão regional imediato. (BRASIL, 2011, n. p.)

Diante o exposto, as instituições públicas e privadas de ensino do território brasileiro são responsáveis pela formação dos educandos/as em condições de itinerância, possibilitando o processo de ensino e aprendizagem com equidade e atendendo as particularidades do seu modo de vida.

No caso do Estado da Paraíba algumas escolas estaduais que acolhem esse público não informa às Gerências de Ensino $^{1}$ sobre a matrícula desses estudantes, igualmente ocorrendo no município de Cajazeiras - PB, lócus da pesquisa em andamento, o que incorre na desatenção às Diretrizes do Conselho Nacional da Educação e, consequentemente impossibilitando a obtenção de informações sobre a quantidade de crianças, jovens e adolescentes circenses que estão na Educação Básica, nas múltiplas escolas do Estado.

Para Yamamura (2012m p. 23) A Fundação Nacional de Artes (FUNARTE), órgão responsável por acompanhar as atividades circenses no Brasil afirma:

\begin{abstract}
Não tem um levantamento sobre a quantidade de circos existentes no território brasileiro, ou mesmo quantos jovens em idade escolar vivem dessa forma. No entanto, estima que existam mais de 500 circos pelo país de diversos tamanhos e condições financeiras. Sendo assim, ainda não é possível quantificar os meninos e meninas de circo que estão fora da escola.
\end{abstract}

A autora destaca que através da Instituição, algumas problemáticas correlacionadas à ausência de informações sobre a quantidade de meninos e meninas que não têm acesso à Educação Básica. Também apresenta, a carência de dados sobre os educandos/as que frequentam as instituições de ensino. Dentre outras evidências, isso demonstra que o Sistema Educacional, a despeito da existência de políticas públicas não contempla a todos/as com o direito ao acesso e a permanência das crianças, jovens e adolescentes em condição de itinerância na Educação Básica, conforme preceitua a Constituição Federal.

\footnotetext{
${ }^{1}$ Denominação dada aos setores responsáveis pela educação, no âmbito das escolas da rede pública estaduais do Estado da Paraíba.
} 
A itinerância da realidade circense traz à tona a necessidade de tempos e espaços diferenciados para os artistas circenses acessarem à educação formal, o que os impossibilita à permanência numa mesma escola durante todo o ano letivo, diferentemente de estudantes que vivem num mesmo espaço. Nesse sentido, Sequeira \& Balanero (2010) enfatiza:

São muitas as crianças que, por causa do trabalho dos pais, se veem obrigadas a constantes deslocações, o que supõe o seu afastamento de um ambiente escolar adequado e a manifesta dificuldade de continuar a escolaridade em condições de igualdade com as outras crianças, situação condicionada pela actual legislação educativa. (SEQUEIRA \& BALANERO 2010, P.10)

Como enfatizado, algumas famílias que trabalham de forma itinerante, no caso os profissionais circenses, pelas próprias características de sua atividade/função, muitas das vezes, sem alternativas, são obrigados a se deslocarem com os filhos/as, mesmo, em faixa etária escolar. E a partir destas condições, crianças, jovens e adolescentes apresentam dificuldades para que possam frequentar às escolas.

Alguns pais e mães, por opção, com a finalidade de priorizar a educação dos filhos e, consequentemente evitar possíveis dificuldades na escolarização os deixa com parentes, o que traz outra preocupação no tocante à sucessão familiar no circo e o distanciamento familiar e dos laços de afetividade, conforme afirmam Sequeira \& Balanero (2010, p. 16):

Os filhos são deixados com um familiar não itinerante, forçados ao corte prolongado de laços afectivos com o núcleo familiar; a escolarização não é interrompida, no entanto, o afastamento demorado da vivência do ambiente familiar nuclear e do circo, é gerador de angústias e vontade constante de regressar, ainda que à custa do abandono escolar, sendo que os resultados escolares reflectem, frequentemente, esse permanente desconforto; cada vez mais os pais rejeitam essa solução, por razões afectivas, e tornam-se absolutamente complacentes com o abandono escolar e o regresso ao circo, sobretudo a partir da adolescência.

Outro problema está na formação de profissionais capacitados para atender esse público. Em algumas universidades a Educação Itinerante para os grupos circenses é uma 
temática inexistente. A ausência nos currículos dos cursos de licenciaturas, sobre a referida temática, sonega informações necessárias para que os docentes no exercício de suas atividades possam contribuir de forma efetiva no ensino e na aprendizagem desses sujeitos.

Assim, esses conhecimentos devem, e/ou deveriam acontecer durante a formação inicial e continuada. Desconhecendo essas peculiaridades, os licenciandos, poderão desenvolver ações que ferem o exercício da docência ao desrespeitar as realidades daqueles sujeitos, como por exemplo: atos que gerem desconfortos durante à matricula e à permanência dos discentes durante as atividades escolares e avaliações, já que, permanecem pouco tempo no espaço escolar.

Consequentemente, todas estas problemáticas citadas, quando não analisadas e discutidas pelas instituições de ensino, podem refletir de modo negativo no processo de ensino/aprendizagem dos discentes, no caso específico dos educandos/as artistas circenses. Para fortalecer a formação docente e abolir possíveis constrangimentos em sala de aula, o Conselho Nacional de Educação (CNE) (BRASIL, 2011) enfatiza, no Art. $5^{\circ}$ :

Os cursos destinados à formação inicial e continuada de professores deverão proporcionar aos docentes o conhecimento de estratégias pedagógicas, materiais didáticos e de apoio pedagógico, bem como procedimentos de avaliação que considerem a realidade cultural, social e profissional do estudante itinerante como parte do cumprimento do direito à educação.

O professor que no processo de formação adquirir as competências citadas terá condições de ensinar aos discentes itinerantes respeitando todas as peculiaridades que englobam, desde sua cultura aos tempos e limites do processo de aprendizagem de cada sujeito. Contribuindo assim, para e na formação básica e cidadã destes/as.

\section{ALGUMAS NOTAS SOBRE O ANDAMENTO DA PESQUISA}

Desde o ano de 2016 que nos debruçamos sobre nossa pesquisa a partir das disciplinas de Práticas de Ensino quando nos deparamos com a exibição de um filme, Abril 
Despedaçado, o qual retratava uma cena fílmica desenvolvida numa história de circo. Chamou-nos a atenção a criança nordestina, Pacu, o qual não lia formalmente, mas ganhou um livro da artista circense e, a partir das imagens do livro devaneava em seus sonhos imaginando o mar e a sereia, como uma característica presente da infância, a partir da qual se espera que haja a aprendizagem nas brincadeiras (ABRIL despedaçado, 2001, cap. 2).

Além do filme, também vinham à memória as experiências da infância quando tinha a oportunidade de assistir aos pequenos circos que se apresentavam na cidade onde resido, Aguiar-PB. Partimos para a nossa pesquisa para pensar como crianças e jovens circenses têm acesso à educação, já que a itinerância é a marca essencial de suas vidas.

Nossas primeiras experiências de pesquisa foram através do Wembley Circo, uma instituição do Estado da Bahia, a qual, no ano de 2016 estava realizando uma turnê no Alto Sertão Paraibano, em específico, na cidade de Cachoeira dos Índios-PB.

O circo em questão, nesse período era constituído por quinze integrantes, entre os entrevistados, quatro pessoas (um homem e três mulheres) frequentaram escolas públicas durante as atividades circenses e, por motivos diversos não conseguiram concluir o Ensino Fundamental; além de uma criança feminina, a qual frequenta as creches dos lugares que os circos realizam suas rotas.

Perguntamos aos integrantes do circo acerca de sua perspectiva de escolarização o que trouxe memórias positivas e negativas acerca do espaço escolar, desde a aceitação até a negação tácita do desejo de recebê-los na escola.

Quadro 1: Percepção dos integrantes do circo “ Wembley Circo" na perspectiva da escolarização dos educandos/as de circo.

\section{Escolarização dos educandos/as de circos: entre o desejo e a realidade}

Entrevistado 1: "Existe um preconceito com relação aos circenses tanto de alguns professores como de alguns alunos por acharem que as pessoas de circo não prestam". 
Entrevistado 2: "Não. existe preconceito, alguns tem o pensamento diferente de nós circenses".

Entrevistado 3: “Não. tem muita discriminação".

Entrevistado 4: "Existem a valorização da cultura circense por parte de alguns alunos e professores".

Entrevistado 4: Certa vez, "A diretora da escola, disse que não havia lugar na sala para mim. Não tinha cadeira, porque estava lotada, e aí, meu tio pegou uma cadeira do circo e levou para a sala de aula e eu fiquei estudando uma semana na escola".

Fonte: Soares, 2016.

Dentre os depoimentos destacamos duas questões acerca de recursos e a avaliação, as quais demonstram a fragilidade nas políticas públicas e ao despreparo na formação docente e da escola para a compreensão da diversidade desses sujeitos. Quanto aos materiais didáticos utilizados nas distintas instituições de ensino, os entrevistados afirmaram que os livros didáticos eram diferentes em cada escola e quando passavam para outra escola teriam que devolvê-los. Quanto à avaliação por parte dos professores, relataram que eram avaliados pela participação nas aulas e, também através de provas. Indagados sobre se sentiam saudades das escolas que frequentaram todos afirmaram que não, por que não tiveram recordações positivas na recepção e despedida nos espaços escolares.

Diante do exposto, podemos analisar que no cenário mágico de suas recordações, no ambiente escolar, esses sujeitos enquanto educandos/as foram vítimas de um sistema de ensino perverso que exclui e segrega-os do direito à educação. Dessa forma, além da participação efetiva da família, é também responsabilidade das instituições governamentais na promoção e efetivação de políticas públicas que favoreçam à permanência dos educandos/as, artistas circenses na escola.

\section{CONSIDERAÇÕES}

Para que uma criança, jovem e/ou adolescente possa frequentar várias escolas nos múltiplos lugares em que os circos fazem suas apresentações, estes/as têm que estarem 
motivados de alguma forma para que possam concluir a Educação Básica. Essa motivação pode vir da família e também da escola, uma vez que, quando não cativados e valorizados a cultura e os saberes prévios dos educandos/as, pode incorrer no abandono imediato da escola e o circo passa ser a única e exclusiva alternativa de organização de vida destes sujeitos e, diga-se de passagem, se constitui um excelente lócus de aprendizagem.

Um educando/a artista circense para ter acesso à escola apresenta uma série de dificuldades como destacado, dependendo de suas funções nas atividades circenses, este enfrenta barreiras decisivas gerando, por vezes, a descontinuidade da formação e, consequentemente a auto-exclusão.

\section{REFERÊNCIAS}

ABRIL Despedaçado. Direção: Walter Salles, produção: Arthur Conh. - São Paulo: Cia das Artes, 2001, 1, DVD. Colorido. Temp. 90 min. - NTSC - 12 anos.

BRASIL. Diretrizes para o atendimento de educação escolar de crianças, adolescentes e jovens em situação de itinerância. Parecer CNE/CEB No: 14/2011. Relatoras: Rita G. do Nascimento e Nilma L. Gomes, Brasília, DF, 07/12/2011. Disponível em: http://etnicoracial.mec.gov.brimagespdfpceb01411educacaoitinerncia.pdf.Acesso:14/03/2017.

BRASIL. Câmara dos Deputados. Projeto de Lei $N^{\circ}$ 3543-A de 2012. Altera a Lei $\mathrm{n}^{\mathrm{o}}$ 6.533, de 24/05/1978. Disponível em: < http://www.camara.gov.br/sileg/integras/980768.pdf>. Acesso em 10 de mar. 2017.

CORDEIRO, L. V. S. Circo além da lona: os processos de organização e produção das artes circenses. Disponível em: <http://www.circonteudo.com.br/stories/documentos /article/3986/CIRCO\%20ALEM\%20DA\%20LONA.pdf > Acesso em: 15 de mar. 2017.

MARCONI, M. A; LAKATOS, E. M. Fundamentos de metodologia científica. - 7. ed.- São Paulo: Atlas, 2010.

PRODANOV, C. C.; FREITAS, E. C. Metodologia do trabalho científico: método e técnicas da pesquisa e do trabalho acadêmico. - 2. ed.- Novo Hamburgo: Feevale, 2013.

SEQUEIRA, H. S. P. M.; BATANERO, J. M. F. Um estudo sobre os alunos itinerantes, filhos dos artistas de circo, no $1^{\circ}$ Ciclo no ensino básico, em Portugal. Disponível em: <https://periodicos.ufrn.br/educacaoemquestao/article/>. Acesso em: 12 de mar. 2017.

YAMAMURA, P. S. Alunos Itinerantes. Disponível em: <http://www.circonteudo.com.br/stories/documentos/article/itinerantes.pdf >. Acesso em: 20 de mar. 2017. 